\title{
Effect of Reinforcement Nanoparticles Addition on Mechanical Properties of SBS/Curauá Fiber Composites
}

\author{
Patricia M Borba ${ }^{a}$, Adriana Tedesco ${ }^{b}$, Denise M Lenz ${ }^{c *}$ \\ ${ }^{a}$ Centro Tecnológico de Polímeros - CETEPO, Serviço Nacional de Aprendizagem Industrial - SENAI/RS, \\ São Leopoldo, RS, Brazil \\ ${ }^{b}$ Braskem S. A., III Pólo Petroquímico, Triunfo, RS, Brazil \\ 'Programa de Pós-graduação em Engenharia de Materiais e Processos Sustentáveis, \\ Universidade Luterana do Brasil - ULBRA, Canoas, RS, Brazil
}

Received: April 24, 2013; Revised: October 30, 2013

\begin{abstract}
Composites of styrene-butadiene-styrene triblock copolymer (SBS) matrix with curauá fiber and/ or a nanoparticulate mineral (montmorillonite clay - MMT) used as reinforcing agents were prepared by melt-mixing. The influence of clay addition on properties like tensile and tear strength, rebound resilience, flex fatigue life, abrasion loss, hardness and water absorption of composites with 5 , 10 and $20 \mathrm{wt} \%$ of curauá fiber was evaluated in presence of maleic anhydride grafted styrene-(ethyleneco-butylene)-styrene triblock copolymer (MA-g-SEBS) coupling agent. Furthermore, the effect of mineral plasticizer loading on tensile strength of selected composites was investigated. The hybrid SBS composite that showed the best overall mechanical performance was composed by $2 \mathrm{wt} \%$ of MMT and $5 \mathrm{wt} \%$ of curauá fiber. Increasing fiber content up to $20 \mathrm{wt} \%$ resulted in a general decrease in all mechanical properties as well as incorporation of $5 \mathrm{wt} \%$ MMT caused a decrease in the tensile strength in all fiber contents. The hybrid composites showed clay agglomerates (tactoids) poorly dispersed that could explain the poor mechanical performance of composites at higher concentrations of curauá fiber and MMT nanoparticles. The addition of plasticizer further decreased the tensile strength while the addition of MMT nanoparticles decreased water absorption for all SBS composites.
\end{abstract}

Keywords: SBS copolymer, montmorillonite, vegetable fiber, mechanical properties

\section{Introduction}

In recent years, technological innovations in the material's development have attracted considerable interest due to the world energy crisis as well as the global concern with the environmental issues. The search for environmental friendly technologies which the main objective is the adoption of less environmentally impactant solutions by the industrial sector has become an imperious need towards a sustainable society.

The use of vegetable fibers in polymer composites as reinforcing agents emerges as an ecologically viable and sustainable alternative to replacement of manufactured fibers. Vegetable fiber reinforced composite materials offer unique properties which can efficiently used in civil and structural applications including buildings and bridges. Also, they can be used in automotive parts, circuit boards, sporting goods and household appliances ${ }^{1}$. Vegetable fibers are environmentally friendly, fully biodegradable, abundantly available, renewable and cheap and also have low density ${ }^{2}$. When vegetable fiber-reinforced plastics are subjected to combustion process or landfill at the end of their life cycle, the amount of $\mathrm{CO}_{2}$ released from fibers is neutral with respect to the assimilated amount during their growth ${ }^{3}$. Curauá fiber is the only such fiber that showed the specific mechanical strength and modulus comparable to glass

*e-mail: denise.lenz@gmail.com fiber ${ }^{4}$. Nevertheless, it is well-known that vegetable fibers absorb moisture due to their hydrophilic nature, show poor wettability and fiber heterogeneity as well as have incompatibility with hydrophobic polymeric matrices. To build composites with improved mechanical properties, therefore, a chemical or physical surface modification of the fibers is necessary ${ }^{5,6}$. These different treatments change the hydrophilic character of the vegetable fibers so that moisture effects are reduced in the composite ${ }^{6}$.

Current works are now focusing on hybridization as a way of undoubtfully reaching noteworthy mechanical properties for composites based on vegetable fibers ${ }^{7}$. The incorporation of different types of reinforcements into a single matrix has led to the development of hybrid composites. The behaviour of hybrid composites is a weighed sum of the individual components in which there is a more favourable balance between the inherent advantages and disavantages. As a consequence, a balance in cost and performance can be achieved through proper material design ${ }^{8}$.

The addition of nanosized inorganic particles, as montmorillonite nanoparticles, in organic polymers shows significant improvements in mechanical properties, water and gas barrier properties as well as flame-retardant properties of the formed nanocomposite at lower nanofiller 
loadings $s^{9,10}$. Montmorillonite (MMT) has a structure of stacked platelets where the thickness of each platelet is around one nanometer and the other dimensions are in the range of several hundred nanometers, resulting in a high interfacial interaction between polymer matrix and clay particles and also high molecular tortuosity for the polymeric molecules ${ }^{1}$.

In recent work, authors ${ }^{11}$ have already fabricated a hybrid composite with jute vegetable fiber and montorillonite nanoclay dispersed in a biodegradable polymer matrix. Properties of the jute based biocomposites were increased with the increase percentage of nanoclay up to $4 \mathrm{wt} \%$ which acted as a nucleating agent in the biodegradable polymer. Similarly, the addition of MMT significantly increased both flexural and tensile modulus of a composite with poli(vinyl chloride) (PVC) matrix and the waste of Eurycoma longifolia (EL) plant. However, the addition of MMT has decreased the flexural and impact strengths of PVC hybrid composites which were lower than EL/PVC composites ${ }^{12}$.

Following this recent composite approach, the aim of this work was to investigate the influence of montmorillonite nanoparticles (MMT) addition to styrene-butadiene-styrene triblock copolymer (SBS) matrix with or without curauá fibers on composite mechanical properties and water absorption. Also, the effect of maleic anhydride grafted styrene-(ethylene-co-butylene)-styrene triblock copolymer (MA-g-SEBS) as coupling agent and a mineral plasticizer on mechanical performance of the composite was evaluated. The novelty of this work lies in the development of a hybrid composite using SBS thermoplastic elastomer as matrix and two distinct reinforcements with the purpose of tailoring the mechanical properties and water absorption of the resulted composite. In addition, the composite was prepared by conventional melt-mixing without any special equipment to manufacture it.

The thermoplastic elastomers SBS and styrene(ethylene-co-butylene)-styrene triblock copolymer (SEBS) comprise a series of synthetic polymers that combine the properties of vulcanized rubber with the processing advantages of conventional thermoplastics. In other words, they allow the production of rubberlike articles using the fast processing equipment developed by the thermoplastics industry. Besides, they can be recycled at the end of their lifecycle ${ }^{13}$. As a result, such copolymers have gained considerable attention in recent years. SBS is mainly used as compatibilizer and impact modifier of polymers and even though it has been widely used for their desirable properties such as flexibility, viscosity, resistance to organic materials, impact resistance and so forth, further modifications of the polymeric properties by various methods have been extensively studied to improve the inherent properties ${ }^{14}$. Thus, the contribution of this work is to disseminate the use of SBS in potential industrial applications such as in footwear (rubber soles), automotive parts, adhesives, wire insulation, packaging, medical devices, toys and plastic dinnerwear ${ }^{15}$ through its melt compounding along with reinforcing agents. A synergistic effect between the different kinds of reinforcements can enhance the overall performance of the composite.

\section{Material and Methods}

SBS (styrene-butadiene-styrene triblock copolymer) supplied by Shell Chemicals Company (Kraton D-1101) with 29-33 wt\% of styrene content and an average molecular weight (Mw) of $92000 \mathrm{~g} / \mathrm{mol}$ was used as the composite matrix and the toughening rubber MA-g-SEBS which is a styrene-ethylene-butylene-styrene triblock copolymer grafted with $2 \mathrm{wt} \%$ maleic anhydride from Shell Chemical (Kraton FG1901X) was used as the coupling agent between curauá fibers and the polymer matrix. The montmorillonite clay (MMT) used was Cloisite 10A, a three-layered clay mineral consisting of silicate sheets which is modified with a quartenary ammonium salt and usually employed as reinforcement for plastics and rubbers ${ }^{16}$. These materials were used as received.

Curauá fibers were supplied from Ituá Agroindustrial (Pará/Brazil) and they were treated with $10 \mathrm{wt} \% \mathrm{NaOH}$ solution for 30 minutes at room temperature, thoroughly washed with water and dried at $100{ }^{\circ} \mathrm{C}$ for $2 \mathrm{~h}$, according to previous work ${ }^{17}$. This treatment promotes cellulose modification ${ }^{6}$. Afterwards, curauá fibers were washed thoroughly with water to remove any $\mathrm{NaOH}$ excess until the $\mathrm{pH}$ of washed water was 7 . Then, curauá fibers were vacuum dried and were milled in a three knives rotatory mill with a $5 \mathrm{~mm}$ mesh sieve (MGHS 2/230 SEIBT Máquinas). Curauá fibers were carefully dried prior to use through heat treatment in an oven at $80{ }^{\circ} \mathrm{C}$ for $24 \mathrm{~h}$ to minimize their moisture content and then loaded at 5, 10 and $20 \mathrm{wt} \%$ along with the polymer matrix. The MA-g-SEBS concentration used was $5 \mathrm{wt} \%$ and MMT nanoclay concentrations were $2 \mathrm{wt} \%$ or $5 \mathrm{wt} \%$ (when both reagents were requested). The employ of paraffinic/naphthenic oil (Shellflex 371 from Shell Oil Company) in concentration of $8 \mathrm{wt} \%$ was evaluated as a plasticizer of the composite. Using a plasticizer, the melt viscosity of the SBS system is expected to reduce due to the plasticization of the phases.

The components were roughly pre-mixed in polyethylene bags before melt-processing. Composites were prepared in a Haake Rheomix internal mixer, equipped with a pair of high shear roller-type rotors with a volume of $3 \mathrm{~cm}^{3}$. The temperature of the mixing chamber was set to $170{ }^{\circ} \mathrm{C}$ and the blending time was $2 \mathrm{~min}$. The rotor rate was set at $60 \mathrm{rpm}$. The obtained composites were subjected to sheeting in a two roll mill.

Composite hardness (shore A scale) was determined using a Bareiss durometer following ASTM $2240^{18}$. Tensile properties and tear strength were evaluated using an EMIC (DL 2000 model) universal testing machine, according to ASTM D 412 - type C standard ${ }^{19}$ and ASTM D 624-C standard $^{20}$, respectively. Flex resistance was measured in accordance with ASTM D $430^{21}$ using a De Mattia flexing machine and rebound resilience measurements were carried out on a Schob pendulum following ISO 4662-2009 specifications $^{22}$. Abrasion measurements were performed according to ISO 4649-2010 23 . For water absorption experiments, composites were immersed in distilled water at room temperature. The water absorption was determined by weighing the samples at regular intervals in an analytical balance with precision of $1 \mathrm{mg}$. 
The morphology of the curauá fibers and MMT nanoparticles as well as their distribution in the composite surface were investigated using a PHILIPS XL 20 scanning electron microscope.

\section{Results and Discussion}

The results for ultimate tensile strength, Young's modulus and elongation at break are shown in Table 1.

Table 1 shows that Young's modulus increases with the increase of the fiber content in the composite, indicating that curauá fibers act as reinforcement to the SBS polymer matrix with or without MA-g-SEBS. Besides, tensile strength increases up to $10 \mathrm{wt} \%$ of fiber, but at higher concentrations (20 wt \%) they decrease. Using MA-g-SEBS as coupling agent, both tensile strength and Young's modulus of composites are higher than those for composites without MA-g-SEBS in all fiber concentrations. As expected, the elongation at break decreases due to the stiffness promoted by the fiber to the composite.

In addition, results showed in Table 1 for SBS/curauá fiber composite with MA-g-SEBS provide important evidence that increasing curauá fiber content in the composite, the concentration of MA-g-SEBS could be higher than $5 \mathrm{wt} \%$ so that mechanical performance of the composite could be improved. For these composites, the increase in fiber content from 5 to $10 \mathrm{wt} \%$ has led to tensile strength enhancement by almost $10 \%$ while the increase in fiber content from 10 to $20 \mathrm{wt} \%$ has caused tensile strength decrease by nearly $20 \%$. In spite of the tensile strength behaviour, Young's modulus always increases.

The use of coupling agent is important for improving mechanical properties of the composites with vegetable fibers, even after fiber treatment ${ }^{24}$. The MA-g-SEBS increases the polarity which leads to better adhesion between fiber and polymer. A more pronounced improvement in tensile properties can be achieved for polymer matrices that exhibit polar groups as in polyesters ${ }^{25}$.

Figure 1a and b shows SEM analysis of tensile fracture cross-section of composites. While Figure 1a (without MA-g-SEBS) revealed a weak fiber/matrix interface with numerous irregularly shaped microvoids and some debondings, Figure 1b shows an improvement in polymer/ fiber adhesion. Thus, poor interfacial bonding causes fiber pullout and micro-spaces between the fiber and matrix which obstruct stress propagation when stress is loaded inducing a gradual decrease in the tensile strength as also reported in other work ${ }^{26}$.

Thus, the next experiments were carried out using $5 \mathrm{wt} \%$ MA-g-SEBS for all composites. Table 2 shows the tensile properties for composites of SBS and montmorillonite clay without curauá fiber and using different concentrations of the fiber.

According to Table 2, using only montmorillonite as reinforcement, the addition of $5 \mathrm{wt} \%$ of MMT is better than

Table 1. Tensile properties: ultimate tensile strength, elongation at break and Young's modulus of SBS/curauá fiber composites and neat SBS* without plasticizer.

\begin{tabular}{lcccccc}
\hline \multicolumn{1}{c}{ Tensile properties } & \multicolumn{2}{c}{$\begin{array}{c}\text { SBS/curauá fiber composite } \\
\text { without MA-g-SEBS }\end{array}$} & \multicolumn{3}{c}{ SBS/curauá fiber composite with MA-g-SEBS } \\
\hline Curauá fiber, \% w/w & $5 \%$ & $10 \%$ & $20 \%$ & $5 \%$ & $10 \%$ & $20 \%$ \\
Ultimate tensile strength, MPa & $6.0 \pm 0.5$ & $6.7 \pm 0.6$ & $4.5 \pm 0.4$ & $7.1 \pm 0.5$ & $7.8 \pm 0.2$ & $6.2 \pm 0.3$ \\
Elongation at break, \% & $250 \pm 31.2$ & $125 \pm 25$ & $40 \pm 1.5$ & $138 \pm 37$ & $110.5 \pm 18$ & $30.5 \pm 0.5$ \\
Young's modulus, MPa & $3.0 \pm 0.2$ & $4.0 \pm 0.2$ & $5.5 \pm 0.3$ & $2.8 \pm 0.3$ & $4.8 \pm 0.2$ & $7.2 \pm 0.4$ \\
\hline
\end{tabular}

*Neat SBS: $4.2 \pm 1.8 \mathrm{MPa}, 645 \% \pm 162.2$ and $2.5 \pm 0.1 \mathrm{MPa}$ for ultimate tensile strength, elongation at break and Young's modulus, respectively (experimental values).

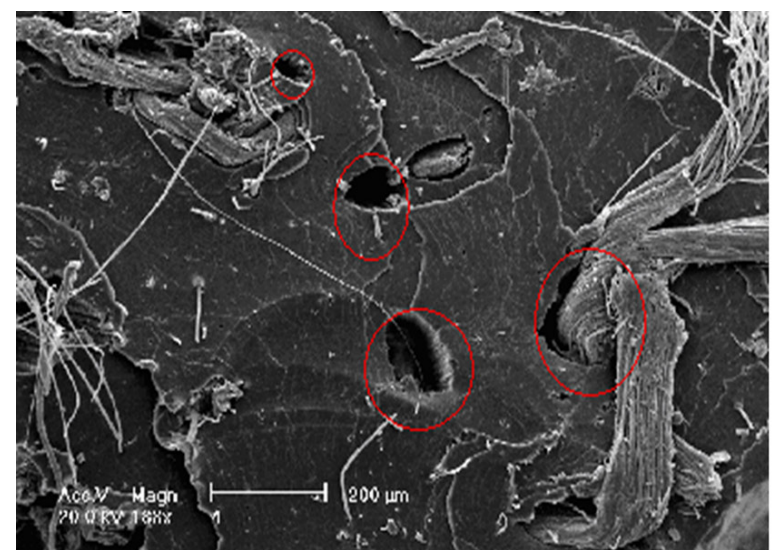

(a)

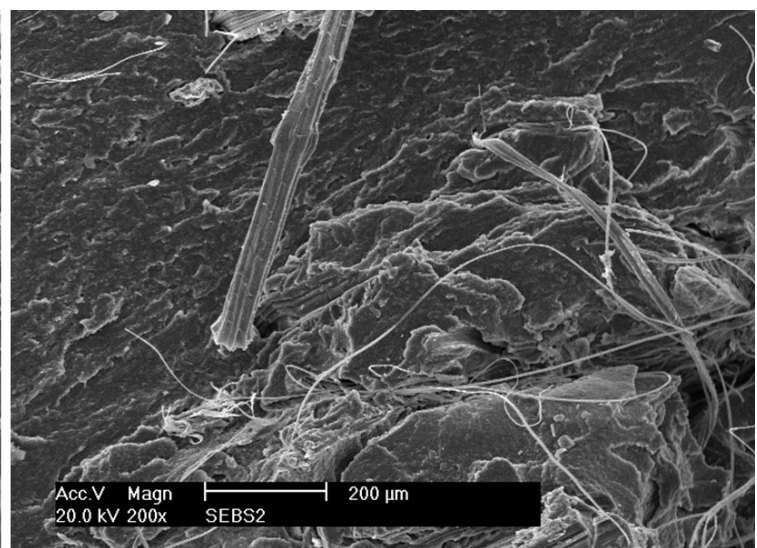

(b)

Figure 1. SEM micrographs of cross-section of SBS composites with different concentrations of curauá fiber (a) without MA-g-SEBS and (b) with MA-g-SEBS. 
$2 \mathrm{wt} \%$ to improve the mechanical strength of the composite. The addition of $5 \mathrm{wt} \%$ of montmorillonite clay to the SBS/ MA-g-SEBS matrix promotes tensile properties similar to the composite SBS/MA-g-SEBS with $10 \mathrm{wt} \%$ curauá fiber (Table 1).

The use of a coupling agent is important even using only MMT as reinforcing agent. Kim et al. ${ }^{27}$ observed that incorporation of below 5 phr silane coupling agent in the MMT/NBR(nitrile rubber) nanocomposites enhances the tensile strength and modulus, but above 5 phr content it decreases these properties. The enhancement of the mechanical properties in MMT/NBR nanocomposites is caused by the better interaction between MMT and NBR.

In addition, Table 2 shows a trend of producing SBS/ MMT/curauá fiber composites that present lower mechanical performance compared to composites with only MMT clay as a function of increasing fiber content up to $20 \mathrm{wt} \%$. Besides, the concentration of $2 \mathrm{wt} \%$ MMT has led to hybrid composites with higher ultimate tensile strengths with respect to composites with $5 \mathrm{wt} \%$ MMT.

Thus, a synergistic effect between MMT and curauá fiber was observed in composites with low concentrations of curauá fiber and MMT (5 wt $\%$ and $2 \mathrm{wt} \%$, respectively) that yielded the highest ultimate tensile strength of all hybrid composites. The ultimate tensile strength was found to decrease at higher loadings of curauá fiber. Increasing MMT concentration to $5 \mathrm{wt} \%$, the ultimate tensile strength decreased more markedly than with $2 \mathrm{wt} \%$ MMT and also it decreased with the increase in fiber content.

Some authors have already reported the use of reinforcements like MMT and cellulosic materials to improve mechanical properties of polymer composites. Zhao et al. ${ }^{28}$ have reported the synergic effects of silane coupling agent and MMT in PVC/wood flour composites. The authors verified that the incorporation of $0.5 \mathrm{wt} \%$ organomodified MMT with silane-treated wood flour in PVC composites increased the composite tensile strength by $9.7 \%$ and the impact strength by $15.4 \%$. However, the impact strength decreased when loading level is above $0.5 \mathrm{wt} \%$, while the tensile strength slightly increased until at $1.5 \mathrm{wt} \%$ and then dropped. The results reported by these authors could corroborate the better mechanical performance of SBS/curauá fiber/MMT composites with lower concentration of montmorillonite clay (2 wt\%).

According to Rozman et al. ${ }^{29}$, the addition of MMT into the kenaf fiber-polyester system showed an improvement in flexural and impact properties up to $1 \%$ MMT. Further increase in the MMT loading had resulted in the decrease in these properties which was believed to be due to MMT agglomeration.

Figure 2 shows SEM micrographs of cross-section SBS/ MA-g-SEBS composites with only MMT (Figure 2a) and with curauá fiber and MMT (Figures $2 b-d$ ). Figure 2a shows the presence of some islands of nanoclay agglomerates known as tactoids uniformly dispersed in SBS matrix. It was not possible to investigate the degree of nanoclay agglomeration by SEM since only microstructures (tactoids) were possible to detect. Fiber unit cells and fiber bundles can be seen in Figure $2 b$ and nonuniform dispersion of nanoclay is presented in Figures $2 b-d$. Figure 2d shows the difference of both reinforcing agents at higher magnification with fiber unit cells presenting rod-like conformation and MMT tactoids are approximately rounded besides the unequal dimensions of curauá fibers and the nanoclay tactoids. However it was not possible to verify if the degree of nanoclay agglomeration was higher in hybrid composites than in composites with only MMT by SEM technique.

Thus, the increase in curauá fiber content in hybrid composites had resulted in the decrease of tensile strength for both concentrations of MMT ( $2 \mathrm{wt} \%$ and $5 \mathrm{wt} \%$ ) probably due to agglomeration of the MMT nanoclay in the presence of the fiber yielding poorly dispersed MMT in the composite. This effect is more pronounced at higher concentrations of MMT (5 wt \%). Both, the non-uniform dispersion and MMT agglomeration at higher concentrations of fiber and MMT could prevent a better stress transfer mechanism in the matrix of composite submitted to tensile forces.

The results for composite hardness followed the results obtained for Young's modulus in tensile experiments, according to Table 3. As the content of fiber and MMT increased, the hardness of SBS composite also increased. Similarly, the use of MA-g-SEBS as coupling agent together with fibers and/or MMT favors hardness increase. The hardness of SBS/MA-g-SEBS composites with $20 \mathrm{wt} \%$ curauá fiber and $5 \mathrm{wt} \%$ MMT increased around $25 \%$ with respect to pure SBS.

Figure $3 \mathrm{a}$ shows the results for tear strength and Figure $3 \mathrm{~b}$ for the rebound resilience. Also, the results for flex-fatigue life, measured in number of cycles, and abrasion loss of neat SBS and its composites are shown in Figures 3c and $d$, respectively.

Table 2. Tensile properties: ultimate tensile strength, elongation at break and Young's modulus of SBS/curauá fiber/montmorillonite composites and neat SBS* without plasticizer.

\begin{tabular}{lcccccccc}
\hline \multicolumn{1}{c}{ Tensile properties } & \multicolumn{7}{c}{$\begin{array}{c}\text { SBS/curauá fiber composites } \\
\text { with MA-g-SEBS }\end{array}$} \\
\hline Curauá fiber, \% w/w & $0 \%$ & $0 \%$ & $5 \%$ & $5 \%$ & $10 \%$ & $10 \%$ & $20 \%$ & $20 \%$ \\
Montmorillonite (MMT), \% w/w & $2 \%$ & $5 \%$ & $2 \%$ & $5 \%$ & $2 \%$ & $5 \%$ & $2 \%$ & $5 \%$ \\
Ultimate tensile strength, MPa & $6.9 \pm 0.2$ & $8.2 \pm 0.2$ & $7.9 \pm 0.1$ & $7.5 \pm 0.1$ & $7.0 \pm 0.1$ & $6.6 \pm 0.3$ & $6.0 \pm 0.2$ & $5.3 \pm 0.3$ \\
Elongation at break, \% & $148 \pm 15$ & $120 \pm 12$ & $128 \pm 10$ & $135 \pm 5$ & $118 \pm 8$ & $115 \pm 7$ & $33 \pm 3$ & $37 \pm 2$ \\
Young's modulus, MPa & $4.0 \pm 0.2$ & $5.5 \pm 0.1$ & $4.8 \pm 0.0$ & $6.6 \pm 0.2$ & $6.8 \pm 0.1$ & $7.4 \pm 0.3$ & $7.9 \pm 0.3$ & $8.5 \pm 0.2$ \\
\hline
\end{tabular}

*Neat SBS: $4.2 \pm 1.8 \mathrm{MPa}, 645 \% \pm 162.2$ and $2.5 \pm 0.1 \mathrm{MPa}$ for ultimate tensile strength, elongation at break and Young's modulus, respectively (experimental values). 
Table 3. Hardness of SBS/curauá fiber/montmorillonite composites and neat SBS* without plasticizer.

\begin{tabular}{lcccccccc}
\hline & \multicolumn{7}{c}{$\begin{array}{c}\text { SBS/curauá fiber composites } \\
\text { with MA-g-SEBS }\end{array}$} \\
\hline Curauá fiber, \% w/w & $0 \%$ & $0 \%$ & $5 \%$ & $5 \%$ & $10 \%$ & $10 \%$ & $20 \%$ & $20 \%$ \\
Montmorillonite (MMT), \% w/w & $0 \%$ & $5 \%$ & $0 \%$ & $5 \%$ & $0 \%$ & $5 \%$ & $0 \%$ & $5 \%$ \\
Hardness (shore A) & $72 \pm 1$ & $77 \pm 1$ & $75 \pm 1$ & $78 \pm 2$ & $77 \pm 1$ & $80 \pm 2$ & $82 \pm 1$ & $86 \pm 3$ \\
\hline
\end{tabular}

*Neat SBS: $69 \pm 1$.

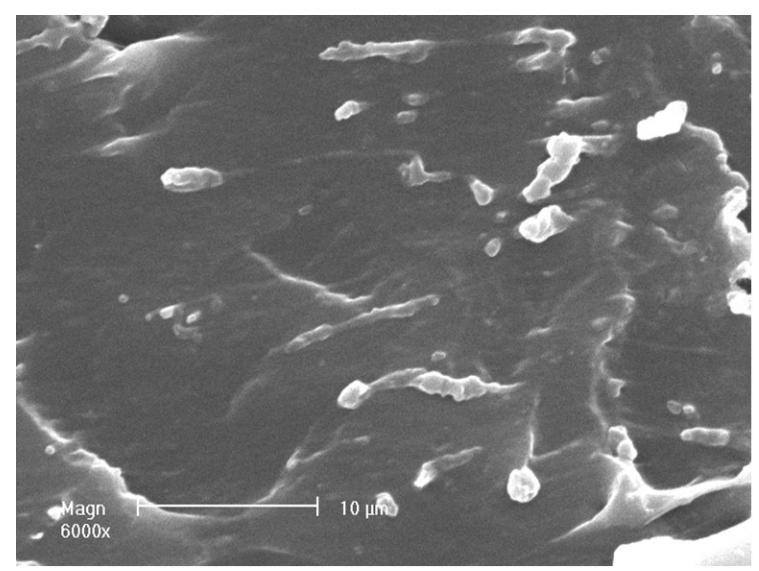

(a)

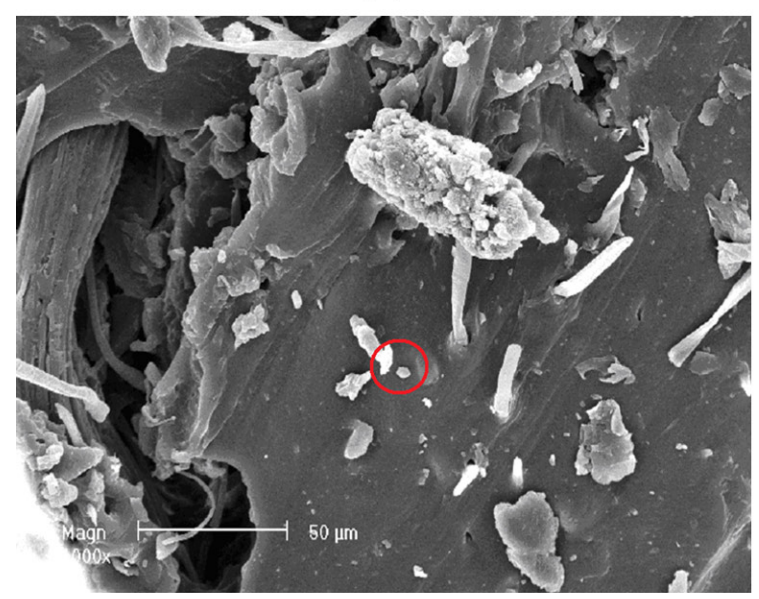

(c)

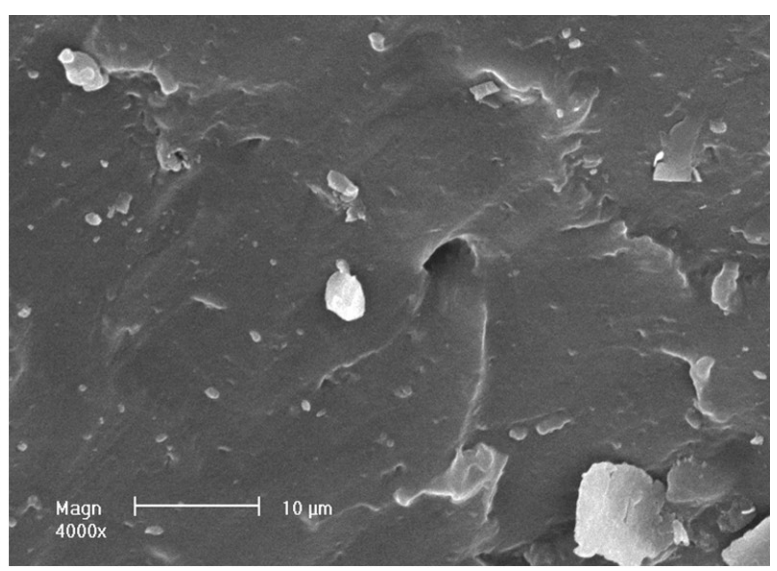

(b)

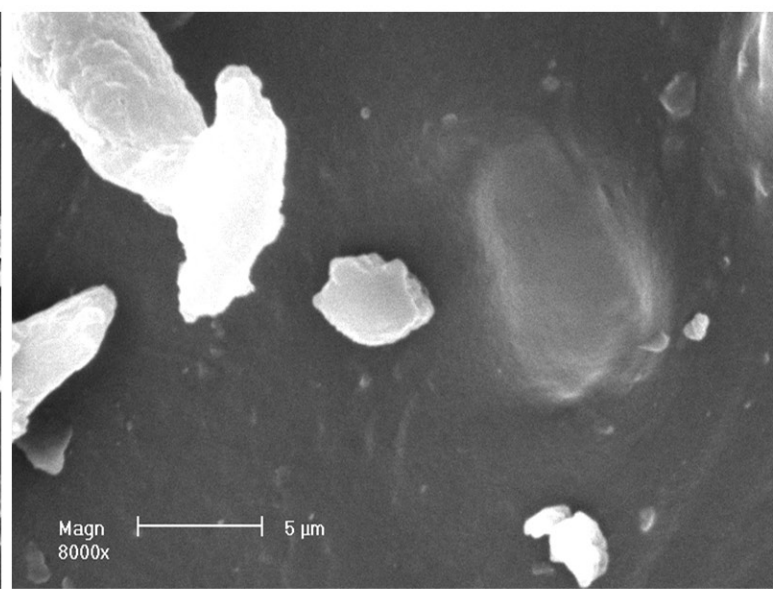

(d)

Figure 2. SEM micrographs of cross-section of SBS/MA-g-SEBS composites with (a) only montmorillonite nanoclay (2 wt\%) and (b, c and d) with $10 \mathrm{wt} \%$ of curauá fiber and $2 \mathrm{wt} \%$ montmorillonite nanoclay. The circle in 2c is detailed in $2 \mathrm{~d}$.

Tear strength has increased with curauá fiber content up to $10 \mathrm{wt} \%$ of fiber and after that this property started to decrease. Besides, the incorporation of $2 \mathrm{wt} \%$ MMT in SBS/curauá fiber composites enhances the tear strength only for composites with $5 \mathrm{wt} \%$ curauá fiber. At higher loadings of curauá fiber, the addition of MMT did not show significant change in tear strength with respect to the composites with the same fiber content. This fact can be also explained probably due to MMT agglomeration as well as the weakness of the interactions of the curauá fiber and MMT with the coupling agent at higher concentrations of curauá fiber.
The rebound resilience has showed similar behaviour as for tear strength. Jurkowska et al. ${ }^{30}$ also noticed an increase in rebound resilience for natural rubber with simultaneous increase in hardness with MMT concentration up to $10 \mathrm{phr}$ in comparison to gum rubber. For very shock-absorbing uses, low rebound compounds are usually used, eg rebound values of $10-40 \%$. For high frequency vibrations or where quick recovery is required, compounds in the $40-65 \%$ rebound values are used.

The flex-fatigue life (Figure 3c) was defined by the number of cycles at which a visible crack appeared in SBS and its composites. These experiments showed that 


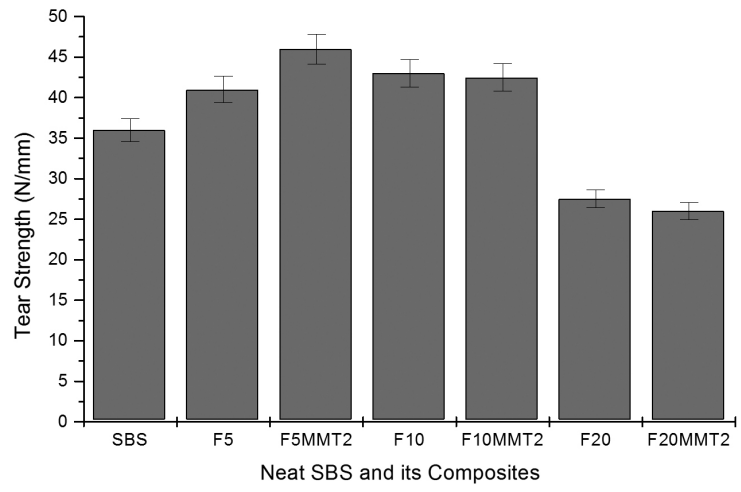

(a)

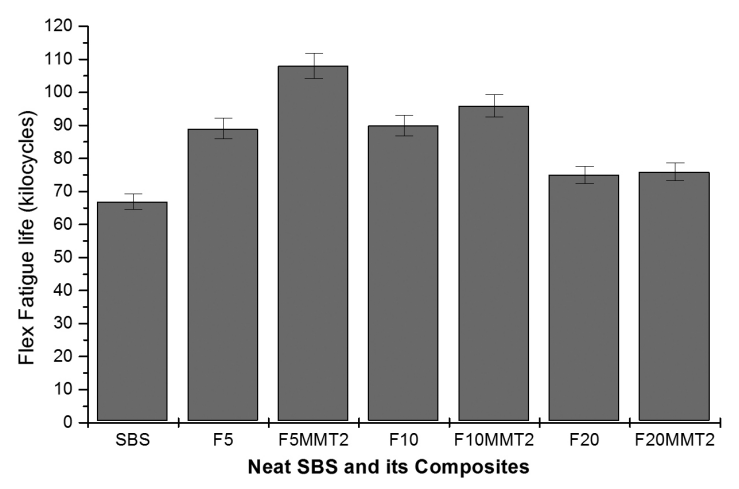

(c)

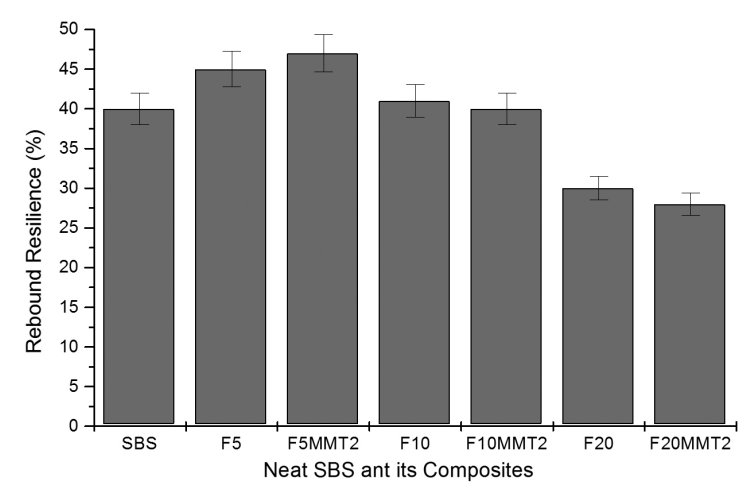

(b)

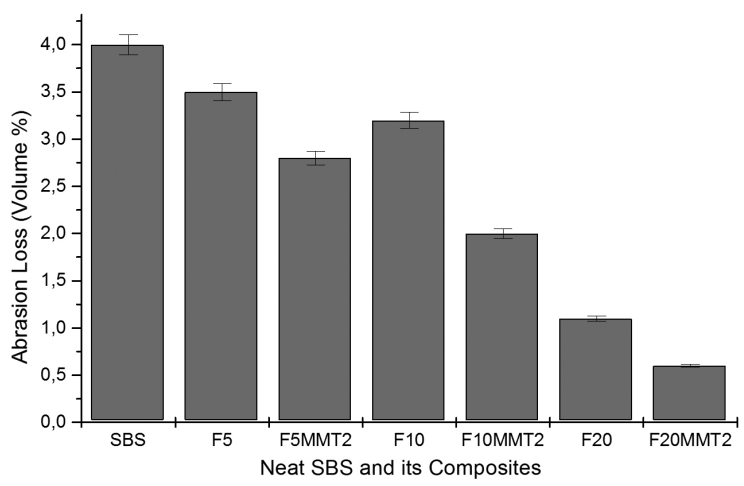

(d)

Figure 3. (a) Tear strength (b) Rebound resilience, (c) Flex resistance and (d) Abrasion loss of neat SBS and SBS/MA-gSEBS composites without plasticizer. SBS - neat SBS, F5 - composites with 5 wt\% curauá fiber, F5MMT2 - composites with 5 wt $\%$ curauá fiber and 2 wt $\%$ of MMT, F10 - composites with 10 wt $\%$ curauá fiber, F10MMT2 - composites with 10 wt $\%$ curauá fiber and $2 \mathrm{wt} \%$ of MMT, F20 - composites with $20 \mathrm{wt} \%$ curauá fiber, F20MMT2 - composites with $20 \mathrm{wt} \%$ curauá fiber and $2 \mathrm{wt} \%$ of MMT.

the addition of $2 \mathrm{wt} \%$ of MMT increase the number of life cycles for SBS/curauá fiber composites with $5 \mathrm{wt} \%$ of fiber content. Using $10 \mathrm{wt} \%$ of fiber content, MMT addition promoted only a slightly increase in the number of cycles and with $20 \mathrm{wt} \%$ of fiber content no significant change in flex resistance was observed as function of MMT addition.

Elastomeric articles like shoe soles are subjected to cyclic stress or deformations. According to $\mathrm{Wu}$ et al. ${ }^{31}$, the fatigue life is closely related to the crack-growth characteristics of the materials. The fatigue-failure process involves initiation of microcracks and propagation of microcracks and/or small naturally occurring flaws, which probably arise from a combination of factors such as fillers, contaminants or voids in the matrix, imperfectly dispersed compounding ingredients and surface flaws. Thus, flex resistance can be associated to tear strength which measures the average resistance to the start of a tear (tear initiation). In fact, besides the type of filler, there are many other factors influencing the fatigue life, such as the degree of crosslinking, the type of polymer matrix and so on. In the neat SBS and its composites there is no crosslinking but the compatibility between the clay and the curauá fiber with SBS matrix supported by MA-g-SEBS coupling agent is very important for better mechanical performance.
Abrasion loss has followed the results for hardness, as expected. For stiffer composites, lower was the abrasion loss. It is important to point out that composites with $5 \mathrm{wt} \%$ of curauá fiber and 2wt\% of MMT showed around $12 \%$ lower abrasion loss than composites with only $10 \mathrm{wt} \%$ of curauá fiber.

Analyzing all results, it is worth to observe the synergetic effect between montmorillonite and curauá fibers in SBS/MA-g-SEBS composites when the concentrations of curauá fibers and MMT were $5 \mathrm{wt} \%$ and $2 \mathrm{wt} \%$, respectively. These composites showed better results for ultimate tensile strength, tear strength, rebound resilience, flex fatigue and abrasion loss when compared with SBS/MA-g-SEBS composites with $10 \%$ curauá fiber.

Some samples of SBS/MA-g-SEBS composites were subjected to tensile stress using $8 \%$ mineral oil. Figure 4 shows the results obtained for tensile experiments. According to this Figure, mineral oil does not interact positively either with curauá fibers or with MMT. However, composites with curauá fibers showed a higher decrease in tensile strength than composites with only montmorillonite clay when mineral oil was employed.

Water absorption experiments are summarized in Figure 5. It was observed that the addition of $2 \mathrm{wt} \% \mathrm{MMT}$ decreased water absorption by around $15 \%$ after 400 hours 


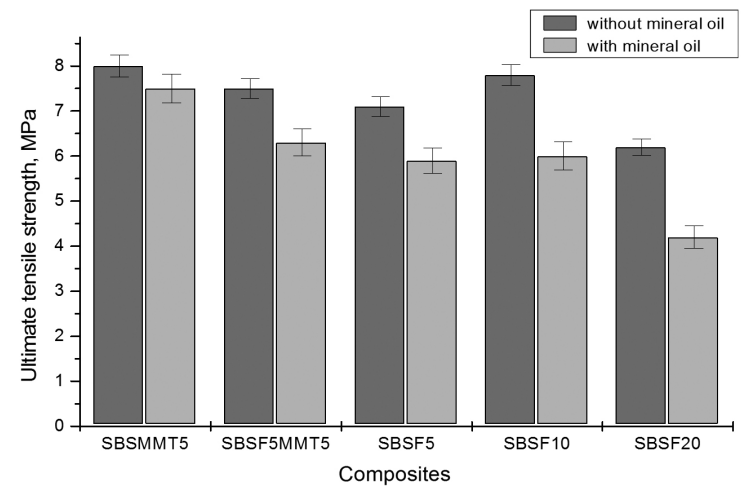

Figure 4. Comparison of tensile strength values of SBS/MA-gSEBS composites with different concentrations of curauá fiber and/ or $5 \mathrm{wt} \%$ of MMT as reinforcing agents with and without mineral oil. SBSMMT5 - composite with 5\% MMT, SBSF5MMT5 - composite with $5 \mathrm{wt} \%$ curauá fiber and $5 \mathrm{wt} \%$ MMT, SBSF5 - composite of with 5 wt $\%$ curauá fiber, SBSF10 - composite with 10 wt $\%$ curauá fiber, SBSF20 - composite with 20 wt \% curauá fiber.

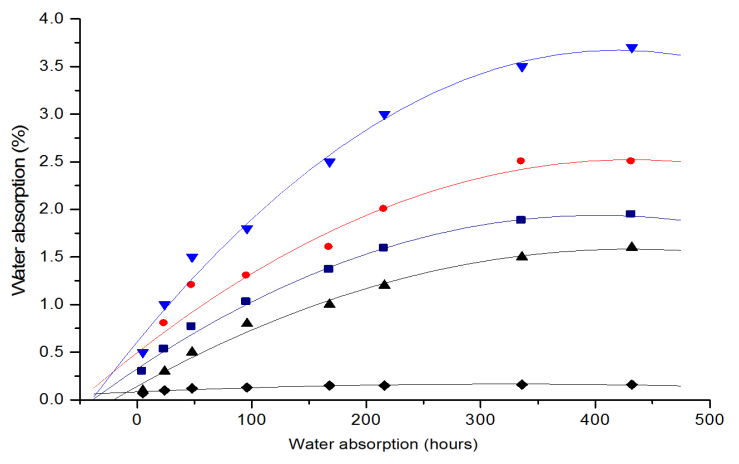

Figure 5. Water absorption of neat SBS and SBS/MA-g-SEBS composites: $\bullet$ neat SBS, $\Delta$ composite with $5 \mathrm{wt} \%$ curauá fiber and $2 \mathrm{wt} \%$ MMT, composite with $5 \mathrm{wt} \%$ curauá fiber, • composite with $10 \mathrm{wt} \%$ curauá fiber and $2 \mathrm{wt} \%$ MMT, $\mathbf{\nabla}$ composite with 10 wt $\%$ curauá fiber.

of experiment for composites with $5 \mathrm{wt} \%$ fiber and around $30 \%$ for composites with $10 \mathrm{wt} \%$ fiber. In the presence of MMT a maze or "tortuous path" structure could form in polymer matrix after blending with MMT which block the normal water channels ${ }^{32}$. Thus, MMT could improve the water resistance of SBS/curauá fiber composites effectively.

\section{References}

1. Goda K, Takagi H and Netravali AN. Fully biodegradable green composites reinforced with natural fibers. In: Thomas $\mathrm{S}$ and Pothan LA, editors. Natural Fibre Reinforced Polymer Composites. Philadelphia: Old City Publishing; 2009. chap. 13, p. 329-360.

2. Taj S, Munawar A and Khan S. Natural Fiber- Reinforced Polymer Composites. Proceedings of the Pakistan Academy of Sciences. 2007; 44(2):129-144.

3. Wambua P, Ivens U and Verpoest I. Natural fibers: can they replace glass in fiber-reinforced plastics? Composites
Besides, the observed decrease in water absorption in presence of MMT clay could be also attributed to the weak polarity of ammonium cation in the Cloisite 10A nanoclay gallery.

\section{Conclusion}

Hybrid composites of SBS matrix with MMT clay and curauá fibers as reinforcing agents were produced. Addition of MA-g-SEBS as coupling agent caused an improvement in the tensile properties of SBS/curaua fiber composites which is due to the promotion of better adhesion between fiber and polymer. Incorporation of $2 \mathrm{wt} \%$ MMT to SBS/5 wt\% curauá fiber composites with MA-g-SEBS produced appreciable increase in composite's properties like tensile strength, hardness, tear resistance, rebound resilience, abrasion resistance and flex resistance. At higher concentrations of curauá fiber up to $20 \mathrm{wt} \%$, tensile strength, tear strength, rebound resilience and flex resistance decreased while hardness and abrasion resistance showed a trend to increase as a function of fiber content. Thus, the concentration of curauá fibers in the hybrid composite plays an important role in determining the composite mechanical performance. Addition of $5 \mathrm{wt} \%$ MMT further decreased the mechanical properties also as function of fiber content. This effect can be attributed to the agglomeration and nonuniform dispersion of MMT particles at higher fiber and MMT concentrations.

Vegetable fibers are known to increase the water absorption of polymeric composites. However, significant decrease in water absorption was observed when MMT nanoparticles were added to all SBS/curauá fiber composites. On the other hand, the use of $8 \%$ mineral oil hasn't succeeded since it decreased the tensile strength of all selected composites. Thus, further studies must be performed in order to improve processability of these composites using plasticizers without considerable changes in their properties. Therefore, this work showed that SBS hybrid composites can be prepared with optimized properties for specific performance requirements.

\section{Acknowledgements}

The authors are grateful to CNPq for financial support.

Science and Technology. 2003; 63:1259-1264. http://dx.doi. org/10.1016/S0266-3538(03)00096-4

4. Leão AL, Machado IS, De Souza SF and Soriano L. Production of curauá (Ananas Erectifolius L.B. SMITH) fibers for industrial applications: characterization and micropropagation. Acta Horticulturae. 2009; 822:227-238.

5. Zhou Z, Liu X, Hu B, Wang J, Xin D, Wang Z et al. Hydrophobic surface modification of ramie fibers with ethanol pretreatment and atmospheric pressure plasma treatment. Surface and Coatings Technology. 2011; 205:4205-4210. http:// dx.doi.org/10.1016/j.surfcoat.2011.03.022 
6. Bledzki AK and Gassan J. Composites reinforced with cellulose based fibers. Progress in Polymer Science. 1999; 24(2):221274. http://dx.doi.org/10.1016/S0079-6700(98)00018-5

7. Amico SC. Vegetable fibers as multifunctional materials Revista Matéria. 2010; 15(2):355-363.

8. Thwe MM and Liao K. Durability of bamboo-glass fiber reinforced polymer matrix hybrid composites Composites Science and Technology. 2003; 63:375-387. http://dx.doi. org/10.1016/S0266-3538(02)00225-7

9. Ash BJ, Siegel RW and Schadler LS. Mechanical behavior of alumina/poly(methylmethacrylate) nanocomposites. Macromolecules. 2004; 37:1358-1369. http://dx.doi. org/10.1021/ma0354400

10. Yang L, Hu Y, Lu H and Song L. Morphology, thermal, and mechanical properties of flame-retardant silicone rubber/ montmorillonite nanocomposites. Journal of Applied Polymer Science. 2006; 99(6):3275-3280. http://dx.doi.org/10.1002/ app. 22756

11. Hossain M K, Dewan M W, Hosur M and Jeelani S. Mechanical performances of surface modified jute fiber reinforced biopol nanophased green composites. Composites: Part B. 2011; 42:1701-1707. http://dx.doi.org/10.1016/j. compositesb.2011.03.010

12. Hamid Y, Bakar A A and Deirram N. Mechanical and morphological properties of waste Eurycoma longifolia fiber/montmorillonite reinforced poly(vinyl chloride) hybrid composites. Journal of Applied Polymer Science. 2012; 128(2):1170-1175. http://dx.doi.org/10.1002/ app.38401

13. Osswald T A, Turng L-S and Gramann P. Injection Molding Handbook. Cincinnati: Hanser Verlag Publications; 2008. 764 p.

14. Lee W-F and Chen Y-J. Graft copolymerization of $\mathrm{N}$-isopropylacrylamide on styrene-butadiene-styrene block. Journal of Applied Polymer Science. 2001; 88(11):2841-2850.

15. Wm. Claude White. Butadiene production process overview. Chemico-Biological Interactions. 2007; 166:10-14. PMid:17324391. http://dx.doi.org/10.1016/j.cbi.2007.01.009

16. Cloisite ${ }^{\circledR} 10 \mathrm{~A}$ technical data sheet. Oonzales, TX.

17. De Paoli M-A, Santos PA, Spinacé MAS, Fermoselli KKG. Polyamide-6/vegetal fiber composite prepared by extrusion and injection molding. Composites: Part A. 2007; 38: 2404-2411. http://dx.doi.org/10.1016/j.compositesa.2007.08.011

18. American Society for Testing and Materials - ASTM. ASTM 2240-05 (Reapproved 2010): Test Method for Rubber Property - Durometer Hardness. West Conshohocken: ASTM; 2010.

19. American Society for Testing and Materials - ASTM. ASTM D412-06 C: Standard Test Methods for Vulcanized Rubber and Thermoplastic Elastomers-Tension. West Conshohocken: ASTM; 2011.

20. American Society for Testing and Materials - ASTM. ASTM D 624-00 C: Standard Test Methods for Tear Strenght of Conventional Vulcanized Rubber and Termoplastics Elastomers. West Conshohocken: ASTM; 2007.
21. American Society for Testing and Materials - ASTM. ASTM D430-06: Standard Test Methods for Rubber DeteriorationDynamic Fatigue. West Conshohocken: ASTM; 2012. http:// dx.doi.org/10.1520/D0430-06

22. International Organization for Standardization - ISO. ISO 4662:2009(E): Rubber, vulcanized or thermoplastic - Determination of rebound resilience. Switzerland: ISO; 2009.

23. International Organization for Standardization - ISO. ISO 4649:2010: Rubber, vulcanized or thermoplastic - Determination of abrasion resistance using a rotating cylindrical drum device. Switzerland: ISO; 2010.

24. Kim H-S, Lee B-H, Choi S-W, Kim S and Kim H-J. The effect of types of maleic anhydride-grafted polypropylene (MAPP) on the interfacial adhesion properties of bio-flour-filled polypropylene composites. Composites: Part A. 2007; 38:14731482. http://dx.doi.org/10.1016/j.compositesa.2007.01.004

25. Harnnecker F, Rosa DS and Lenz DM. Biodegradable Polyester-Based Blend Reinforced with Curauá Fiber: Thermal, Mechanical and Biodegradation Behaviour. Journal of Polymers and the Environment. 2012; 20(1):237-244. http:// dx.doi.org/10.1007/s10924-011-0382-5

26. Islam MN, Rahman MR, Haque MM and Huque MM. Physicomechanical properties of chemically treated coir reinforced polypropylene composites. Composites: Part A. 2010; 41:192198. http://dx.doi.org/10.1016/j.compositesa.2009.10.006

27. Kim J-T, Lee D-Y, Oh T-S and Lee D-H. Characteristics of nitrile-butadiene rubber layered silicate nanocomposites with silane coupling agent. Journal of Applied Polymer Science. 2003; 89:2633-2640. http://dx.doi.org/10.1002/ app.12169

28. Zhao Y, Wang K, Zhu F, Xue P and Jia M. Properties of poly(vinyl chloride)/wood flour/montmorillonite composites: Effects of coupling agents and layered silicate. Polymer Degradation and Stability. 2006; 91:2874-2883. http://dx.doi. org/10.1016/j.polymdegradstab.2006.09.001

29. Rozman HD, Rozyanty AR, Musa L and Tay GS. Ultra-violet radiation-cured biofiber composites from kenaf: The effect of montmorillonite on the flexural and impact properties. Journal of Wood Chemistry and Technology. 2010; 30(2):152-163. http://dx.doi.org/10.1080/02773810903259565

30. Jurkowska B, Jurkowski B, Oczkowski M, Pesetskii SS, Koval V and Olkhov YA. Properties of MontmorilloniteContaining Natural Rubber. Journal of Applied Polymer Science. 2007; 106(1):360-371. http://dx.doi.org/10.1002/ app. 26657

31. Wu Y-P, Zhao W and Zhang L-Q. Improvement of FlexFatigue Life of Carbon-Black-Filled Styrene-Butadiene Rubber by Addition of Nanodispersed Clay. Macromolecular Materials and Engineering. 2006; 291:944-949. http://dx.doi. org/10.1002/mame.200600114

32. Ray SS and Okamoto M. Biodegradable polylactide and its nanocomposites: Opening a new dimension for plastics and composites. Macromolecular Rapid Communications. 2003; 24:815-840. http://dx.doi.org/10.1002/ marc. 200300008 